\title{
Introdução ao Dossiê «Juventudes e Músicas Digitais Periféricas»
}

Frank Marcon, ${ }^{1}$ Livia Jiménez Sedano ${ }^{2}$ e Otávio Raposo ${ }^{3}$ UFS, Aracaju-SE, Brasil / INET-md, UNL / CIES-IUL, Lisboa, Portugal

Nos últimos anos, uma série de ritmos musicais foram gerados e difundidos no triângulo pós-colonial entre África, América e Europa e que estão a se projetar a nível global, como: a kizomba, o kuduro, o rap, o funk, o forró, a salsa, o brega, entre outros. Tais expressões musicais e as suas correspondentes práticas de dança têm se globalizado a um ritmo vertiginoso através das migrações internacionais, dos congressos internacionais de dança (Soares 2015) e de plataformas comunicativas na era/geração digital (Feixa 2014), tais como youtube, spotify e facebook (Hutchinson 2014).

Esses ritmos têm invadido espaços sonoros cotidianos tanto na internet quanto em canais de televisão, rádios comerciais, espaços públicos e pistas de dança de ambos os lados do Attântico (Kabir 2014). Nesses trânsitos musicais, de pessoas e de experiências, também emergem questões de poder implicadas pelas diásporas e pelas memórias relativas ao colonialismo e aos locais de origem, provocando um senso de percepção e de sensibilidade estética particulares em contextos fortemente influenciados pela globalização do consumo cultural. Neste sentido, importa ressaltar as sociabilidades alternativas e os estilos de vida inovadores que emergem desses processos, passíveis, por vezes, de subverterem as dinâmicas de segregação urbana, o racismo, a pobreza e a violência, ou contracenarem com elas.

O papel de mediação de sentidos sociais através da música tem se mostrado intenso nas pistas de dança, bares, associações, ruas, bairros e outros espaços públicos, muitos deles associados às experiências sociais de marginalização, articulados a presença migratória ou às experiências de imaginários culturais diaspóricos. Produtores, DJs, MCs, músicos e dançarinos são

1 Professor de Antropologia na Universidade Federal de Sergipe. Coordenador do Grupo de Estudos Culturais, Identidades e Relações Interétnicas, com registro no Diretório de Grupos de Pesquisas do CNPq. Contato: marconfrank@hotmail.com

2 Antropóloga e investigadora em pós-doutoramento no Instituto de Etnomusicologia da Universidade Nova de Lisboa, onde desenvolve o seu projecto "Etnicidades dançantes num mundo social transnacional" com bolsa da FCT (Fundação para a Ciência e Tecnologia) desde 2012. Contato: liviajs@fcsh.unl.pt

3 Pós-doutorando em Antropologia com bolsa da Fundação para a Ciência e a Tecnologia (FCT) e investigador integrado do Centro de Investigação e Estudos de Sociologia (CIES-IUL), no Instituto Universitário de Lisboa (ISCTE-IUL). Contato: otavio_raposo@iscte-iul.pt 
alguns dos agentes que dinamizam rituais de produção musical e reuniões dançantes, articulando polifonias de discursos e sentidos sobre tais experiências.

As novas tecnologias e redes digitais são basilares nesses processos, ao propiciar que artistas vinculados às áreas marginalizadas dos centros urbanos possam romper com o bloqueio da indústria cultural hegemônica e dos modos de legitimação do consumo e do gosto estético. A multiplicação de estúdios caseiros nas margens das cidades e a difusão de videoclipes com milhões de visualizações são exemplos das novas possibilidades dos artistas periféricos se fazerem visíveis. A maior horizontalidade nas dinâmicas de produção musical, decorrentes da revolução tecnológica das últimas duas décadas (Marcon 2015; Aderaldo e Raposo 2016) tem redimensionado o poder sobre a circulação e o consumo musical, principalmente entre jovens.

Quando lançamos a proposta deste dossiê, ${ }^{4}$ tinhamos o objetivo de refletir sobre as práticas artísticas e os rituais de sociabilidade e performance protagonizados por jovens em áreas ou em condições socialmente marcadas por processos de precarização. De fato, não queríamos abordar quaisquer juventudes, mas aquelas pertencentes às classes sociais desfavorecidadas e que são, tantas vezes, estigmatizadas pelos discursos político-institucionais que os culpabilizam pelos episódios de violência (e decadência) urbana. Isto porque, embora sejam enunciados no campo do desvio e da marginalidade pela mídia sensacionalista, a crescente importância das expressões artísticas dessa "juventude periférica" vem lhes conferindo uma nova visibilidade como demonstraram diversos autores (Caldeira 2012, Raposo 2016, Bertelli e Feltran 2017).

De modo bem abrangente, a ideia inicial deste dossiê era reunir artigos de pesquisadores interessados em debater o papel desses jovens na emergência, expansão e consumo das dinâmicas artísticas vinculadas à música e à dança através de equipamentos digitais. Para isto, lançamos o desafio de aceitar artigos em uma perspetiva antropológica, embora interdisciplinar, aberta também às contribuições de outras disciplinas afins. O resultado que obtivemos foi bastante estimulante, pois dos artigos aceitos foi possível extrairmos algumas considerações interessantes que buscamos articular nesta apresentação.

\section{Música/Dança como Crítica Decolonial}

Pela abrangência do Cadernos de Arte e Antropologia, pela nossa inserção enquanto pesquisadores ou por coincidência, os artigos submetidos e aceites abarcaram estudos empíricos envolvendo experiências em várias cidades localizadas em diferentes países de Língua Portuguesa.

Tal singularidade se tornou interessante para pensarmos a música digital em um terreno linguístico e político específico, que alguns denominam de lusófono ${ }^{5}$. Em grande medida, a

4 A ideia deste dossiê surgiu como continuidade de nossas reflexões sobre o tema, após a realização do Painel 24 “DJs, Músicos e Práticas Dançantes: ritmos, rituais e narrativas na diáspora”, que coordenamos em 2016, no VI Congresso da Associação Portuguesa de Antropologia em Coimbra, Portugal.

5 O debate sobre o conceito de "lusofonia" é vasto e polêmico. A principal crítica com relação ao uso desta expressão, e com a qual concordamos, é sobre o sentido que ela carrega como definidora de um espaço de "cultura portuguesa" ou de um "modo português de estar no mundo", matizados pela ideia de uma língua e uma história em comum. O que merece ser entendido criticamente é a base colonialista deste entendimento sobre a diferença e a alteridade, pois concebe a noção de lusofonia como apologia ao que hoje seria o "produto cultural, político e econômico" do que fora o Império Português em África, na América e na Ásia. 
produção e o consumo de linguagens e de práticas sonoras e corporais abordadas neste dossiê estão marcadas pela colonialidade/decolonialidade de poderes e saberes (Mignolo 2007, Quijano 2000, Castro-Gómez e Grosfogel 2007) que perpassam tal experiência colonial/pós-colonial implicadas pelo trânsito e pelo contato entre Portugal, Brasil e África. Este ambiente transnacional tratado aqui, em que as experiências com a música circulam para além de espaços nacionais e cujas peculiaridades se relacionam não apenas com as redes migratórias, mas também com os trânsitos de símbolos e de mercadorias, se assemelham com a concepção de Paul Gilroy (2001) sobre o "Atlântico Negro", como um amplo espaço de encontros e disputas.

Os estilos de música e dança estudados aqui são, na sua maioria, produzidos e consumidos a partir de imaginários e repertórios de experiências de dominação que implicam pobreza, marginalização social ou imigração de sujeitos e grupos que criaram e criam suas formas de sentir, interpretar e falar sobre o mundo em contextos de agências e poder adversos. Por exemplo, os "bregueiros" que apresentam Picanço e Leistner e os "kuduristas" e "funkeiros" que analisa Faria são sujeitos que se expressam a partir de lugares sociais à margem do poder, cujo acesso aos direitos humanos, à política formal, à cidadania e ao consumo não é plena. Neste sentido, entendemos como música digital periférica, os ritmos produzidos em formato digital por fora das estruturas do poder econômico, em que prevalecem as condições de vida precárias de seus agentes.

Mesmo contra a força de tais estruturas de hierarquização e contra as adversidades vivenciadas no dia a dia por aqueles que estão distantes dos centros de poder e de saber, emergem expressões e estilos musicais que se contrapõem aos valores simbólicos e estéticos hegemônicos e universalizadores. Aliás, também é através das expressões musicais e de dança que o "subalternizado fala" para o mundo (Spivak 1988), envia a sua mensagem numa linguagem que constitui uma forma de codificar e transmitir saberes (cf. Daniel 2005, Grau 1998, Jiménez 2018), mesmo quando deslegitimada pelo poder colonial (cf. Quijano 2000). Esta mensagem espalha-se facilmente e torna-se ainda mais potente por via das novas tecnologias de comunicação digital e a sua acessibilidade.

As ligações históricas e concretas entre os diversos estilos tratados nos artigos apresentados aqui (forró, funk, kizomba, kuduro, pagode e brega) têm relação com as memórias, os afetos e os movimentos de pessoas e de bens materiais e simbólicos que circularam e circulam a margem dos processos hegemônicos de poder, mesmo quando o fizeram em função disto ou condicionados por estes. A música e a dança advindas destas experiências revelam uma forma de estar no mundo que até algumas décadas atrás era invisibilizada - para além de seus espaços de criação - pela perseguição policial, pela vigilância moral e pelo monopólio das corporações sobre a indústria cultural, a produção e o consumo musical. $\mathrm{O}$ advento das tecnologias e redes digitais contribuiu decisivamente para a projeção de manifestações artísticas até então afastadas dos espaços hegemônicos de consumo, rompendo com os bloqueios destes controles por via de um circuito de trocas econômicas e simbólicas que tendem a estimular intercâmbios de conhecimento e projetos culturais autônomos pelo mundo (Canclini et al. 2012, Yúdice 2007). No caso específico deste dossiê, ressaltamos o contorno de uma dada mobilidade humana em um espaço demarcado aqui por Angola, Brasil, Cabo Verde, Espanha, Guiné-Bissau e Portugal e o alcance linguístico desta difusão musical.

O forró, o funk, o kuduro e a kizomba são analisados aqui como expressões lúdicas e de resistência produzidas em redes transnacionais que envolvem diferentes lugares como Lisboa, 
Luanda e Rio de Janeiro, mesmo que circulando para além de seus espaços sociais de criação, quando acompanhando os movimentos de migração. $\mathrm{O}$ caso do tecnobrega trabalhado por Picanço e Leistner, assim como o pagode baiano explorado por Chagas, por outro lado, são analisados como estilos que localmente emergiram a partir do que foi a diáspora africana para o Brasil, mais especificamente sobre como esta experiência é vivenciada em Belém (PA) e em Salvador (BA). Há um elemento importante a ser considerado, alguns destes estilos também passam paradoxalmente a ter seus sentidos disputados no mercado de consumo cultural, a exemplo do forró, que, tal como explicam Nascimento e Ortega, se tornou símbolo de consumo de uma ideia de brasilidade em Portugal e na Espanha. Paralelamente, a kizomba e o kuduro se tornaram em Portugal símbolos de consumo de uma ideia de africanidade, como podemos ver no texto de Jiménez. Em ambos os casos, a colonialidade do poder está em questão, quando se busca "incluir" o exótico no cardápio de oferta de bens culturais e se apropriar do controle sobre a espontaneidade da produção destas expressões. De certo modo, a tentativa de domesticar certos elementos considerados incômodos e agressivos, quando apelam à sensualização e à sexualização, por exemplo, se baseiam nas ideias essencialistas e etnocêntricas que produzem a sensação de pânico moral frente a linguagem musical e ao "corpo indisciplinado do outro", considerado imoral e ameaçador, como veremos em alguns dos contributos neste dossiê. O texto sobre o pagode baiano de Ledson Chagas e o artigo de Faria onde compara o funk e o kuduro são especialmente ilustrativos.

Várias das histórias destes estilos vinculam sonoridades e plasticidades ao passado da escravidão e ao presente de marginalização social em que ainda vivem muitos dos classificados como "africanos" e/ou "negros", categorias com uma carga colonial que ainda hoje as ciências sociais arrastam (cf. Quijano 2000). Tais estilos advém de longos processos de disputas e conflitos contrários a uma "globalização de-cima-para-baixo" (Santos 1997), iniciados com a estruturação de um sistema mundo de poder assimétrico (Mignolo 2003), que substituiu as velhas relações coloniais e tem fundamentado projetos de mercado e de ordem política global homogêneos. No contexto da música e da dança, os estilos produzidos e consumidos a partir das experiências do colonialismo e do racismo e que hoje ganham maior visibilidade como expressões sonoras e plásticas tem se construído como contraponto estético e moral de contestação destes valores globais.

É importante, ainda, dimensionarmos os usos das tecnologias e dos suportes utilizados como meios de produção, de circulação e de consumo da música no presente, que possibilitaram fazeres mais autônomos de criação musical e novas formas de compartilhamento e de circulação de músicas por fora do circuito das grandes empresas fonográficas, suportadas a partir de plataformas digitais móveis. Talvez ainda mais interessante, quando nos cercamos de um contexto social transnacional de idioma comum, como o caso da Língua Portuguesa, é o alcance do acesso aos repertórios musicais presentes e acessíveis pela internet em todos os cantos do planeta em que estejam os falantes desta língua. Os casos do kuduro e do funk analisados por Faria assim como o tecnobrega que nos apresentam Picanço e Leistner dão boa mostra deste tipo de fenômenos.

Todos os estilos tratados neste dossiê se encaixam no que denominamos de música digital, cujo avanço e popularidade têm relação com as peculiaridades que permitem maior mobilidade e alcance, a menor custo. Esta permite que a produção seja realizada a partir de computadores pessoais e samplers, passíveis de transformar pequenas divisões domésticas em estúdios caseiros. Não por acaso, os estúdios, antes inacessíveis para os músicos amadores, se proliferaram nas 
periferias urbanas, abrindo possibilidades para que seus ritmos alcançassem públicos mais amplos, atingindo desde aqueles que se identificam socialmente com a sonoridade e a linguagem da música, àqueles que se engajam com a plasticidade da dança.

O brega, o forró, o funk, a kizomba, o kuduro e o pagode baiano fazem parte de um mesmo sistema de mercado global de circulação da música e da dança contemporâneos, embora partam de experiências sociais situadas, ganhando diferentes dimensões nos contextos em que são produzidos e consumidos. Neste sentido, para além de compreendermos tais dinâmicas de mercado micro/macro, local/global e de poder colonial/decolonial, hegemônico/contra-hegemônico é importante nos perguntarmos quem são os agentes de produção destes estilos; quais suas motivações; como estas sonoridades circulam e de que modos e em função de que elas são consumidas. O que, em alguma medida, todos os artigos deste dossiê exploraram em seus estudos e talvez nos levem a entender melhor o que está em disputa, para além do gosto pela música e pela dança.

\section{Paradoxos entre Etnicidade e Globalização nas Expressões Musicais Periféricas}

Outra questão é como certas expressões artísticas oriundas das antigas colônias e das periferias das grandes cidades, cujos protagonistas são maioritariamente imigrantes daquelas regiões ou afrodescendentes, se tornaram parte integrante de um circuito comercial de dimensão global, quando as mesmas eram, inicialmente, marginalizadas e consideradas de mal gosto pelo mercado. Uma pista de entendimento é de que para entrar nos ditos circuitos, tais expressões são, por vezes, reformuladas simbolicamente com vistas a se encaixarem na ideia de lusofonia (cf. Vanspauwen 2013, 2014). Por exemplo, afirmam-se estilos "exóticos" a partir de uma africanidade reinventada ao gosto do público "branco" de classe média (cf. McMains 2016, Goertzen e Azzi 1999, Robinson 2010) para fazerem parte de um ethos cosmopolita que alegoriza a memória e a utopia colonial portuguesa (cf. Almeida 2000). Os casos do kuduro, a kizomba, o funk e o forró que vários dos autores deste dossiê trabalham, proporcionam ótimos exemplos destes processos.

De outro modo, alguns artigos aqui expostos trazem também exemplos de como a kizomba e o kuduro são apresentados ao público consumidor como expressões de uma presença angolana (e africana) em Portugal, o mesmo ocorrendo com o forró enquanto expressão da presença brasileira em Lisboa e em Valência. Também importa considerarmos que o brega, o funk e o pagode baiano são pensados em outros artigos aqui publicados como experiências periféricas e "negras" nas cidades de Belém (PA), Salvador (BA) e Rio de Janeiro (RJ). Em todos os casos podemos entendê-los pelo prisma étnico-racial, no sentido de que são estilos que emergiram a partir das experiências de grupos sociais reconhecidos como diferentes por alguma ideia de alteridade cultural, social ou fenotípica na relação com outras alteridades maioritários.

Algumas formas de construir etnicidade e/ou afirmar uma negritude, mais concretamente africanidade no Brasil e em Portugal, e a brasilidade em Lisboa e em Valência, nos faz voltarmos ao tema do ser e do poder. Desde esta perspectiva, destacamos aqui as formas em que os diferentes estilos musicais e de dança, tratados neste dossiê, se tornam símbolos de pertença "africana" e/ou "negra" ou "brasileira" nas situações concretas em que são descritas em cada um dos artigos. Por exemplo, no texto de Nascimento e Ortega podemos observar como no Brasil 
o forró é associado a região nordestina; na Espanha e no contexto internacional o forró é associado ao Brasil; em Valência o forró é uma comunidade de práticas de dança distinta de outras práticas, como os salseros. Já o kuduro, seguindo as pistas dadas por Faria e Jiménez, pode ser um emblema de africanidade ou da angolanidade em Portugal ou no Brasil; mas em Angola, o kuduro é símbolo das juventudes dos bairros marginalizados, os musseques. O mesmo ocorre com o funk (Faria), o pagode baiano (Chagas) e o brega (Picanço e Leistner) nas cidades brasileiras, que são estilos que representam os jovens pobres e moradores dos bairros precários, mas associados também ao "ser negro" e aos significados sociais negativos que isto pode representar.

Nos parece que aí estão implicadas questões de ordem hegemônica e contra-hegemônica de poder, que merecem nossa atenção quando tentamos entender como estes estilos se tornam ao mesmo tempo uma oportunidade de estar no mundo - para os imigrantes e as juventudes marginalizadas que agenciam através destas expressões suas possibilidades econômicas de subsistência e de sociabilidade -, mas também o quanto estas formas de estar no mundo se tornam produtos culturais no mercado global de símbolos, estilos de vida e gostos, que reforçam alguns estereótipos coloniais sobre raça, sexualidade e cultura ou criam outros (McMains 2016, Robinson 2006).

No processo de mercantilização destes estilos, a forma como se representam as africanidades constitui um assunto central. No contexto de reforço dos estereótipos de hiper-sexualidade e risco moral que já falamos anteriormente, encontramos fenômenos paradoxais interessantes como a associação de conotações positivas. Assim, a ideia de África está sendo associada a uma autenticidade ou inocência prístina que os "mais evoluídos" consumidores nos centros hegemônicos já perderam - o que Baumann e Gingrich (2004) denominam "gramática orientalista -, a origem da humanidade e das relações sociais e até fonte de cura para os problemas do mundo tardo-moderno. Podemos ver exemplos claros destes fenômenos trabalhados neste dossiê nos artigos de Jiménez em relação à comercialização da kizomba nas escolas de dança e de Nascimento e Ortega no que diz respeito ao forró. Desta forma, o paradoxo consiste na justaposição das ideias de africanidade como risco para o equilíbrio social e como modo de sanar a sociedade. Não é coincidência que no mercado de estilos musicais e de dança (como o forró, kizomba, ou a salsa), a "cultura africana" seja apresentada como uma forma de ultrapassar o individualismo (cf. McMains 2016), a agressividade e os males do mundo capitalista, tudo associado às capacidades curativas do outro exotizado: brasileiro, africano, caribenho. Ao mesmo tempo, em outros contextos de prática, estas músicas e danças são associadas a agressividade, a hiper-sexualidade, a desordem e a desestruturação. Esta união de opostos constitui uma parte importante do seu atrativo para certos públicos, fazendo com que o consumo de aulas de dança pelas classes médias seja experimentado como um aventureiro percurso pelo voluptuoso "mundo africano" sem correr os riscos associados - no imaginário das elites - de visitar discotecas e espaços de socialização da cidade etiquetados como "marginais" e/ou "africanos".

Todas as formas de música e dança tratadas neste dossiê envolvem discussões em algum nível pertinentes aos sentidos morais que são disputados sobre ações, corpos e linguagens idealizadas e estereotipadas. O brega, o funk, o forró, a kizomba, o kuduro e pagode baiano são exemplos de estilos musicais performáticos. Todos estão envolvidos por processos culturais afetivos que acabaram por se constituir como parte do mercado de lazer e do prazer de dançar e de fazer / ouvir música. 
Para além da invasão do espaço sonoro através de circuitos globais, a irreverente performance corporal das danças produz uma versão renovada da escandalização advinda de entendimentos coloniais sobre o "outro". Neste dossiê, Ledson Chagas faz uma viagem histórica que ilustra esta ideia de forma muito clara. A exibição de uma sexualidade associada a desordem social ajuda paradoxalmente a dar visibilidade a esses discursos, embora atacando diretamente as contradições morais das sociedades hegemônicas; de como estes agentes estão no mundo e de como expressam a partir daí a tensão colonial entre corpos disciplinados e indisciplinados, conceitos centrais na análise de Chagas. Em todos os casos aqui apresentados, em que a dança é parte fundamental na análise, os corpos dos sujeitos periféricos são postos como elemento de distinção pela sua capacidade para ir além da vergonha que exibem os corpos "disciplinados". Assim, o habitus (Bourdieu 1991) de civilidade hegemônica, associada à inibição de gestos com conotações sexuais, torna-se no contexto social destas danças emergentes e periféricas, numa performance conservadora reveladora de um analfabetismo corporal. Para além disto, as performances musicais e de dança também se traduzem em capital econômico, como no caso dos $\mathrm{Dj}$ s, dos músicos, dos produtores e dos dançarinos.

Em suma, os artigos deste dossiê apresentam interessantes relações entre certos estilos de dança e música e seus significados sociais, implicados por disputas e negociações de sentido local e global sobre identidades, mercados, territórios, corpos e sexualidades, valendo a pena ressaltarmos resumidamente o enfoque de cada artigo.

Livia Jiménez Sedano no seu artigo “Ritual roles of 'African nights' Djs” propõe analisar os encontros dançantes em Lisboa como rituais contemporâneos nos quais a estrutura social pós-colonial é negociada ao ritmo de músicas como a kizomba, o semba, o kuduro e o afrohouse. Combinando a perspectiva antropológica e da Etnomusicologia, o principal objeto de análise são os roles que os DJs desenvolvem, quando no contexto do clube as hierarquias do dia a dia ficam temporalmente suspendidas e emergem formas inovadoras de socialização.

Ricardo Nascimento e Raúl Ortega partem do conceito de economia cultural e afetiva para descrever as formas como o forró, gênero oriundo do Nordeste brasileiro, tem sido transnacionalizado e apropriado nas escolas de dança através das redes migratórias. No artigo intitulado "Microeconomias afetivas globais do forró na península ibérica" partem de uma etnografia multisituada para comparar o fenômeno em Lisboa (Portugal) e Valência (Espanha), analisando como os espaços de dança se tornam contextos para construir sociabilidades alternativas.

Miguel de Nazaré Brito Picanço e Rodrigo Marques Leistner analisam os modos como o estilo "tecnobrega" e as "festas de aparelhagem" a ele associadas tornam-se elementos de identificação para jovens residentes nos bairros periféricos de Belém, cidade do Norte do Brasil. Neste texto que tem por título "Por entre os palcos das festas de aparelhagem: performances corporais, objetos tecnológicos e identidades juvenis "bregueiras". A noção de encantamento relativo aos dispositivos tecnológicos das festas constitui um eixo central da análise, assim como a relação entre movimentos de agentes humanos e não humanos.

Ledson Chagas traz a perspectiva dos Estudos Culturais para este Dossiê com uma análise histórica do pagode baiano no artigo "Notas sobre a dimensão histórica de corporeidade e seu estudo no contexto de gêneros e cenas musicais juvenis contemporâneos: o caso do pagode baiano". O autor põe o foco nos traços eróticos das danças afro-brasileiras e nos conflitos e 
estereótipos a que são associadas desde os tempos coloniais, tendo como base os conceitos de "matrizes culturais", "repertório" e "corporeidade".

Faria estabelece uma interessante comparação entre dois gêneros associados aos jovens moradores de áreas socialmente marginalizadas em Angola e no Brasil: o kuduro angolano e o funk brasileiro. No seu trabalho "Narrativas musicais contemporâneas entre o local e o global: o caso do funk brasileiro e do kuduro angolano", a autora destaca a agência destes jovens no processo de criação, produção e divulgação dos seus estilos musicais e de expressão corporal através das novas tecnologias mais acessíveis, assim como a capacidade de contestar os discursos negativos projetados sobre eles desde os centros hegemônicos.

\section{Considerações e Agradecimentos}

Para finalizarmos, esperamos que as questões tratadas aqui despertem diferentes interpretações aos leitores e estudiosos dos diferentes estilos de música e dança no presente. Para nós, o principal eixo de reflexão deste dossiê diz respeito ao modo como tais estilos de dança e música tem se tornado "janelas de análise" das relações de poder, das relações de desigualdade social, geracional, étnico racial, de gênero e de sexualidade. Sem contar que a especificidade dos estilos tratados aqui também é a relação contemporânea com as tecnologias digitais, que revolucionaram as dinâmicas e as agências do fazer, de circular e do consumir música e dança na atualidade.

Dizemos isto pensando que estivemos também buscando articular algumas das reflexões advindas de nossas pesquisas individuais sobre o kuduro (Marcon 2015), sobre a kizomba (Jimenez, neste dossiê) e sobre o hip-hop (Raposo 2016) ao que os pesquisadores incluídos neste dossiê vêm realizando neste campo. O que encontramos foi certa afinidade conceitual e certa coerência em alguns pontos de entendimento que consideramos interessantes como forma de compreensão sobre o fenômeno e como forma de apontarmos alguns aspectos gerais do conjunto de artigos aqui publicados. Assim sendo, entendemos que: 1) a música e a dança local/ global continuam sendo formas de expressões pelas quais são transmitidas memórias e valores morais e pelas quais se disputam territórios, estatutos e posições políticas; 2) as novas tecnologias e as criatividades da geração digital potencializaram a visibilidade e a dimensão destas expressões em contextos outrora marcados pela massificação da produção e do consumo ditado exclusivamente pelas grandes corporações do entretenimento; 3 ) os principais agentes destes processos são as juventudes que através do uso das tecnologias digitais tornam a linguagem da música e da dança o seu campo de discurso e a sua expertise criativa para dizer algo sobre seus afetos e sobre seu modo de interpretar e de agir sobre o mundo; 4) tais questões estão diretamente ligadas ao modo como emergem destas expressões as disputas entre valores morais, econômicos e políticos hegemônicos e contra-hegemônicos sobre classe, sobre raça, sobre geração, sobre gênero e sobre sexualidade, entre outros.

Por fim, esperamos que este dossiê nos permita compreender melhor estas questões, que seja um estímulo às novas reflexões neste campo de estudos e que destes artigos emerjam outras situações empíricas e outros problemas de pesquisa. Outras cidades, outros países, outros agentes, outras circunstâncias podem contribuir para reforçar algumas das interpretações aqui arroladas ou lançar novas nuanças analíticas. Por ora, só nos resta agradecermos a todos os que submeteram seus artigos, aprovados ou não, por terem participado do processo; agradecemos 
aos pareceristas anônimos e ao labor de toda a equipe editorial da CAA. Depois de muito trabalho de leitura e de análise dos artigos, de diálogos com os autores através de pareceres, acreditamos que o resultado final traga uma visão inovadora sobre este contexto emergente de produção e consumo da música digital periférica na cena global. Desejamos a todos e todas uma excelente leitura!

\section{REFERÊnCIAS BIBLIOGRÁFICAS}

Aderaldo, Guilhermo e Otávio Raposo. 2016. "Deslocando Fronteiras: notas sobre intervenções estéticas, produções culturais e mobilidade juvenil em áreas segregadas de São Paulo e Lisboa". Revista Horizontes Antropológicos, 22(45): 279-305.

Almeida, Miguel Vale de. 2000. Um Mar da Cor da Terra. "Raça", Cultura e Politica da Identidade. Oeiras: Celta.

Baumann, Gerd e André Gingrich. 2004. “Foreword.” Em Gerd Baumann e André Gingrich (eds.) Grammars of identity/alterity. A Structural Approach. New York e Oxford: Oxford University Press.

Bentley, George. 1987. Ethnicity and Practice. Comparative Studies in Society and History 29 (1): 24-55.

Bertelli, Giordano e Feltran, Gabriel de Santis (Orgs.). 2017. Vozes à Margem:periferias, estética e politica. São Carlos: EDUFSCar/CEM.

Bourdieu, Pierre. 1991. El sentido práctico. Madrid: Taurus.

Caldeira, Teresa Pires do Rio. 2012. Inscrição e circulação: novas visibilidades e configurações do espaço público em São Paulo. Novos Estudos CEBRAP. n. 94, pp.31-67.

Canclini, Nestor García; Francisco Cruces e Maritza Pozo (orgs). 2012. Jóvenes, Culturas Urbanas y Redes Digitales. Barcelona: Ariel.

Castro-Gómez, Santiago e Ramón Grosfoguel (eds.) (2007) El giro decolonial. Reflexiones para una diversidad epistémica más allá del capitalismo global. Bogotá: Siglo del Hombre Ediciones.

Daniel, Yvonne. 2005. Dancing Wisdom. Embodied Knowledge in Haitian Vodou, Cuban Yoruba, and Babian Candomblé. Illinois: University of Illinois Press.

Feixa, Carles. 2014. De la generación @ a la \# generación: la juventud en la era digital. Barcelona: NED.

Gilroy, Paul. 2001. O Atlântico negro: modernidade e dupla consciência. São Paulo: Editora 34.

Goertzen, Chris e Maria Susana Azzi. 1999. Globalization and the Tango. Yearbook for Traditional Music 31:67-76.

Grau, Andrée. 1998. "On the Acquisition of Knowledge: Teaching Kinship through the Body among the Tiwi of Northern Australia." Em Verena Keck (ed.) Common Worlds and Single Lives: Constituting Knowledge in Pacific Societies. Oxford/New York: Berg.

Hutchinson, Sidney. 2014. "Dancing in Place. An Introduction." In Sidney Hutchinson (ed.) Salsa World. A Global Dance in Local Context. Philadelphia, Pennsylvania: Temple University Press.

Yúdice, George. 2007. Nuevas tecnologias, música y experiencia. Barcelona: Gedisa.

Jiménez Sedano, Livia. 2018. "Dancing with children in the field: on the relevance of embodied knowledge and its methodological consequences." Ethnography and Education, DOI: 10.1080/17457823.2018.1447386 
Kabir, Ananya J. 2014. "Oceans, Cities, Islands: Sites and Routes of Afro-Diasporic Rhythm Cultures." Atlantic Studies: Global Currents.

Marcon, Frank. 2015. "Música Digital, Juventudes e Formas de Socialização através do Kuduro. Revista Vivência." Natal, EdUFRN 45: 45-56

McMains, Juliet. 2016. “"Hot” Latin Dance: Ethnic Identity and Stereotype.” Em Anthony Shay and Barbara Sellers-Young (eds.) The Oxford Handbook of Dance and Ethnicity. Oxford and New York: Oxford University Press: 480-500.

Mignolo, Walter D. 2003. Histórias Locais/Projetos Globais. Colonialidade, saberes subalternos e pensamento liminar. Belo Horizonte: EdUFMG.

Mignolo, Walter D. 2007. "Introduction: Coloniality of Power and De-colonial thinking." Cultural Studies 21 (2-3): 151-167.

Okamura, Jonathan Y. 1981. "Situational Ethnicity." Ethnic and Racial Studies 4 (4): 454-465.

Quijano, Aníbal. 2000. "Coloniality of Power, Eurocentrism, and Latin America." Nepantla: Views from the South 1(3): 533-580.

Raposo, Otávio. 2016. "Cartografia da dança. Segregação e estilos de vida nas margens da cidade”. Revista Mana, 22(3): 765-797.

Robinson, Danielle. 2006. ““'Oh, You, Black Bottom!” Appropriation, Authenticity and Opportunity in the Jazz Dance Teaching of 1920s." New York. Dance Research Journal 38 (1\&2): 19-42.

Robinson, Danielle. 2010. "The Ugly Duckling: the Refinement of Ragtime Dancing and the Mass Production and Marketing of Modern Social Dances". Dance Research: The Journal of the Society for Dance Research 28(2): 179-199.

Santos, Boaventura Sousa. 1997. "Por uma concepção multicultural de direitos humanos". Revista Critica de Ciências Sociais 48: 11-32.

Soares, André Castro. 2015. Entre Luanda, Lisboa, Milão, Miami e Cairo. Difusão e Prática da Kizomba. Tese de Mestrado inédita. Lisboa: ISCTE-IUL. Universidade Nova de Lisboa.

Spivak, Gayatri C. 1998. “Can The Subaltern Speak?”. Em Cary Nelson e Lawrence Grossberg (eds.) Marxism and the Interpretation of Culture.

Vanspauwen, Bart Paul. 2014. "O Festival Musidanças: uma análise discursiva da programação e dos manifestos (2001-2012).” Em Moisés de Lemos Martins et al. (eds.) Interfaces da lusofonía. Centro de Estudos de Comunicação e Sociedade: Universidade do Minho.

Vanspauwen, Bart Paul. 2013. "Cultural struggles in the lusofonia arena: Portuguese-speaking migrant musicians in Lisbon." Afrika Focus 26: 67-88.

Wimmer, Andreas. 2013. Ethnic Boundary Making. Institutions, Power, Networks. Oxford: Oxford University Press. 